\title{
Fabrication of the Pre-Series Wide Aperture Superconducting Quadrupoles for the LHC Insertions
}

\author{
G. A. Kirby, N. Catalan Lasheras, R. Ostojic, R. Burgmer, M. Jordan, D. Krischel, and P. Schmidt
}

\begin{abstract}
Individually powered superconducting quadrupoles with a coil bore of $70 \mathrm{~mm}$ will be installed in the LHC insertions, in areas where increased geometrical acceptance and improved field quality are required. The quadrupoles feature a four-layer coil, designed on the basis of two graded $8.3 \mathrm{~mm}$ wide Rutherford-type NbTi cables. The magnets have a magnetic length of $3.4 \mathrm{~m}$ and a nominal gradient of $160 \mathrm{~T} / \mathrm{m}$ at $4.5 \mathrm{~K}$ and $3610 \mathrm{~A}$. A total of 26 quadrupoles are in production at ACCEL Instruments (Germany). In this report we present the experience in fabrication of the pre-series magnets and the results of the initial qualification tests.
\end{abstract}

Index Terms-Insertions, LHC, quadrupoles, superconducting.

\section{INTRODUCTION}

$\mathbf{T}$ HE optics flexibility of the LHC insertions is provided by individually powered quadrupoles in the dispersion suppressors and matching sections. A special wide aperture superconducting quadrupole (MQY), featuring a $70 \mathrm{~mm}$ aperture coil, was developed for these sections of the collider [1]. A number of these magnets will be installed in the LHC experimental insertions, and in other areas of the collider where increased geometrical acceptance and improved field quality are required.

Following the development program [2], the contract for fabrication of $26 \mathrm{MQY}$ quadrupoles was awarded to ACCEL Instruments (Germany), and the first pre-series magnet delivered to CERN for testing in September 2003. In this report we present the experience in fabrication of the first magnets and the results of the initial qualification tests.

\section{DESIGN OF THE MQY QUADRUPOLES}

The MQY wide-aperture quadrupole consists of two $3.6 \mathrm{~m}$ long individually powered apertures assembled in a common yoke structure, Fig. 1. The $70 \mathrm{~mm}$ aperture coils have four layers. The inner two layers are wound and cured together using two graded $8.3 \mathrm{~mm}$ wide Rutherford-type NbTi cables. The two cables are joined in the middle of the second layer. The outer two layers are wound with a single length of the smaller cable. The coils are assembled using a self-supporting collar system, locked with eight full-length tapered keys. The collared coils are assembled in the two-in-one yoke structure using four keys at the poles, which center the assemblies once the laminations

Manuscript received October 20, 2003.

G. A. Kirby, N. Catalan Lasheras, and R. Ostojic are with the CERN, Accelerator Technology Division, 1211 Geneva 23, Switzerland (e-mail: Glyn.Kirby@cern.ch).

R. Burgmer, M. Jordan, D. Krischel, and P. Schmidt are with the ACCEL Instruments, Bergisch Gladbach, Germany.

Digital Object Identifier 10.1109/TASC.2004.829048

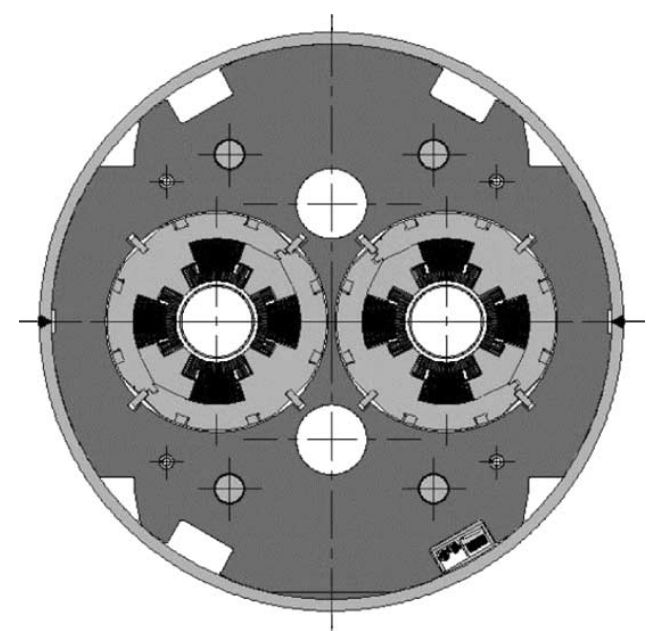

Fig. 1. Cross-section of the MQY matching quadrupole.

TABLE I

MAIN PARAMETERS OF THE MQY WIDE APERTURE QUADRUPOLE

\begin{tabular}{|c|c|c|}
\hline Coil inner diameter & \multicolumn{2}{|c|}{$70 \mathrm{~mm}$} \\
\hline Magnetic length & \multicolumn{2}{|c|}{$3.4 \mathrm{~m}$} \\
\hline Operating temperature & \multicolumn{2}{|c|}{$4.5 \mathrm{~K}$} \\
\hline Nominal gradient & \multicolumn{2}{|c|}{$160 \mathrm{~T} / \mathrm{m}$} \\
\hline Nominal current & \multicolumn{2}{|c|}{$3610 \mathrm{~A}$} \\
\hline Peak field in coil & \multicolumn{2}{|c|}{$6.1 \mathrm{~T}$} \\
\hline Quench field & \multicolumn{2}{|c|}{$7.5 \mathrm{~T}$} \\
\hline Stored energy per aperture & \multicolumn{2}{|c|}{$141 \mathrm{~kJ} / \mathrm{m}$} \\
\hline Inductance per aperture & \multicolumn{2}{|c|}{$21.7 \mathrm{mH} / \mathrm{m}$} \\
\hline Cable parameters & Cable 1 & Cable 2 \\
\hline Width $(\mathrm{mm})$ & 8.3 & 8.3 \\
\hline Mid-thickness (mm) & 1.285 & 0.845 \\
\hline Keystone angle (deg.) & 2.16 & 1.05 \\
\hline No of strands & 22 & 34 \\
\hline Strand dia. $(\mathrm{mm})$ & 0.735 & 0.475 \\
\hline $\mathrm{Cu} / \mathrm{SC}$ Ratio & 1.25 & 1.75 \\
\hline Filament dia. $(\mu \mathrm{m})$ & 6 & 6 \\
\hline $\mathrm{j}_{\mathrm{c}}\left(\mathrm{A} / \mathrm{mm}^{2}, 4.2 \mathrm{~K}\right.$ and $\left.5 \mathrm{~T}\right)$ & 2670 & 2800 \\
\hline
\end{tabular}

are in place. The main parameters of the quadrupole are given in Table I.

\section{FAbrication of the PRE-Series Magnets}

\section{A. Coil Winding}

Two types of MQY coils, layers 1-2 and 3-4, were wound using the counter-rotating technique on a rotating winding machine. To date 17 layer 1-2 coils and 21 layer 3-4 coils were completed. In the following we describe the coil winding and curing process.

Winding of a layer 1-2 coil started with gluing of Cable 1 in the layer jump. The first layer was then wound, the insulating 


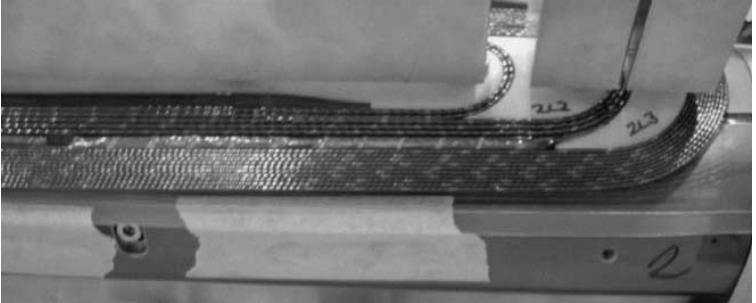

Fig. 2. View of layer 2 with the internal joint between the two types of cable.

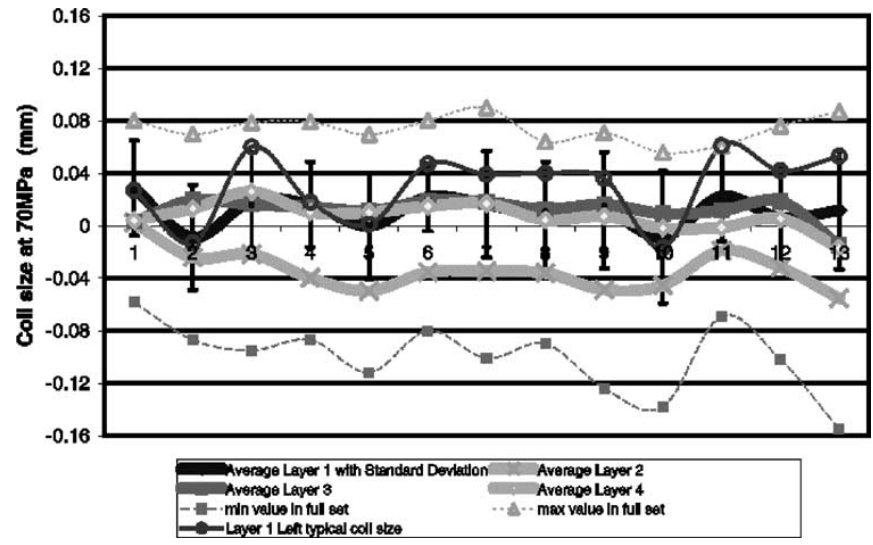

Fig. 3. Longitudinal variation of the azimuthal size in the pre-series coils.

sheet placed on top, and the second layer wound over the insulating sheet. The ends were held in place with a set of adjustable clamps. As two types of cable are used, a soldered joint was made part way through layer 2, using a mould for controlling the size and temperature $\left(223^{\circ} \mathrm{C}\right)$ of the joint. The joint was then insulated and wound into the coil, as shown in Fig. 2. Winding of layer 3-4 coil followed the same procedure, using only a single length of Cable 2.

In preparation for coil curing, a set of short bars, which are part of the curing mould, was mounted on both sides of the coil. The mandrel with the coil was moved to the curing press, and the clamps that hold the coil on the mandrel were removed leaving the coil free to adjust in the mould. The holes in the layer-jump (used to bolt the layer-jump onto the mandrel during winding) were filled with G11 pins, which were glued in before curing. The steel cover sheet and the solid one-piece curing mould were then mounted onto the coil assembly. The curing mould was heated and cooled with a hot oil system, so that the curing cycle took about $21 / 2$ hours. The bonding was achieved at the precisely controlled temperature of $185^{\circ} \mathrm{C}$, where the coil stays for thirty minutes.

After curing, the straight sections of each coil were measured in 13 longitudinal positions. Each measurement point has five $20 \mathrm{~mm}$ long pressure transducers which cover both layers. The coil was placed in a cavity which corresponds to its nominal size at $70 \mathrm{MPa}$, calibrated beforehand with a precision master piece. Before taking a measurement, the coil was cycled three times to $100 \mathrm{MPa}$. The coil size, relative to the design at $70 \mathrm{MPa}$, was measured on the descending part of the cycle. The data were used to determine if a change of curing shim size was needed, and to check that the coil pre-stress at nominal size is within the $70 \pm 10 \mathrm{MPa}$ target. Coils that were outside this range

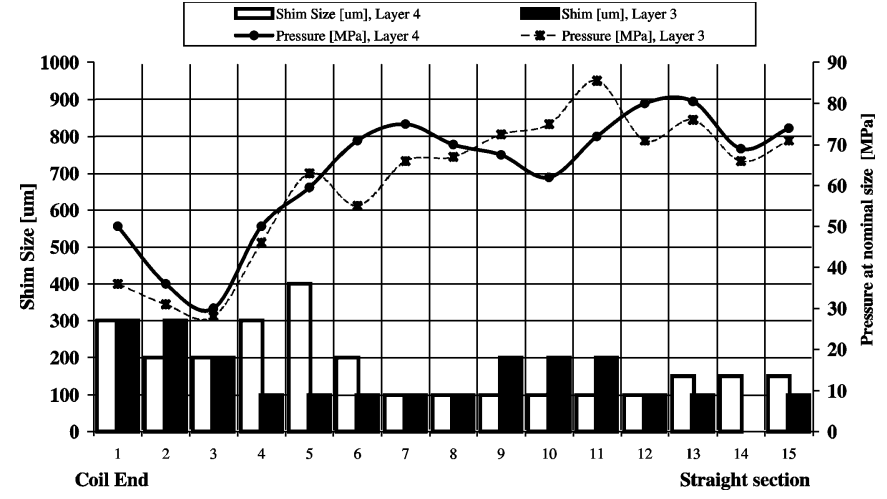

Fig. 4. Pre-stress and shim profile in the lead end of a layer 3-4 coil.

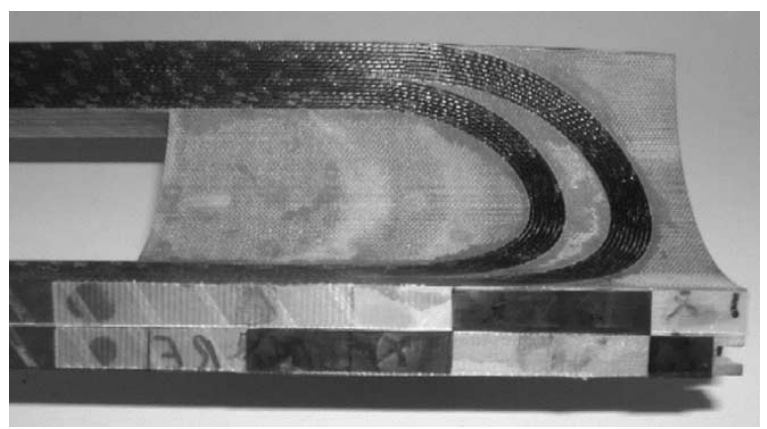

Fig. 5. Shims in the median plane of a layer 3-4 coil lead end.

were re-cured. For modifying the coil size, shims of $0.05 \mathrm{~mm}$ to $0.3 \mathrm{~mm}$ were added or removed from the standard $2 \mathrm{~mm}$ bar. Shimming of the curing cavity by $0.1 \mathrm{~mm}$ changes the coil size by about $0.05 \mathrm{~mm}$. The lower boundary of $60 \mathrm{MPa}$ for the coil pre-stress was taken as a hard limit. However, the upper boundary of $80 \mathrm{MPa}$ was taken as a soft limit and pre-stresses of 90-95 MPa were accepted. The average coil sizes after re-curing were very close to the design value, Fig. 3 . As the average value is not sufficient to ensure a well-supported coil, local undersize in the straight sections was corrected by placing $0.05 \mathrm{~mm}$ adhesive polyimide tape on the mid-plane. Also, to control the low and high pre-stresses in each aperture, several coil configurations were analyzed, and the one with the best pre-stress distribution chosen for the assembly.

In the coil ends, shims were glued to the mid-plane surfaces to control the pre-stress, as shown in Figs. 4 and 5. The target for the pre-stress in the ends is to match the straight section pre-stress on the layer jump side, and to reduce the pre-stress to between $20 \mathrm{MPa}$ and $35 \mathrm{MPa}$ at the coil extremity. To measure and shim the ends, the coil end was placed in a fixed volume closed by the measurement press. The five $20 \mathrm{~mm}$ long pressure transducers were used to measure the pre-stress profile. The values were recorded and shim material was added in the low pre-stress areas. This was an iterative process and took several cycles. The final shim sizes used in the ends were in between $0.1 \mathrm{~mm}$ to $0.4 \mathrm{~mm}$. The shimming of the two coil ends and the measurement of the straight sections took about the same time as winding and curing of the coils. It is expected that following the experience with the pre-series coils a standard shim can be used as a starting point for shimming, reducing the time for measuring and shimming the coil ends. 


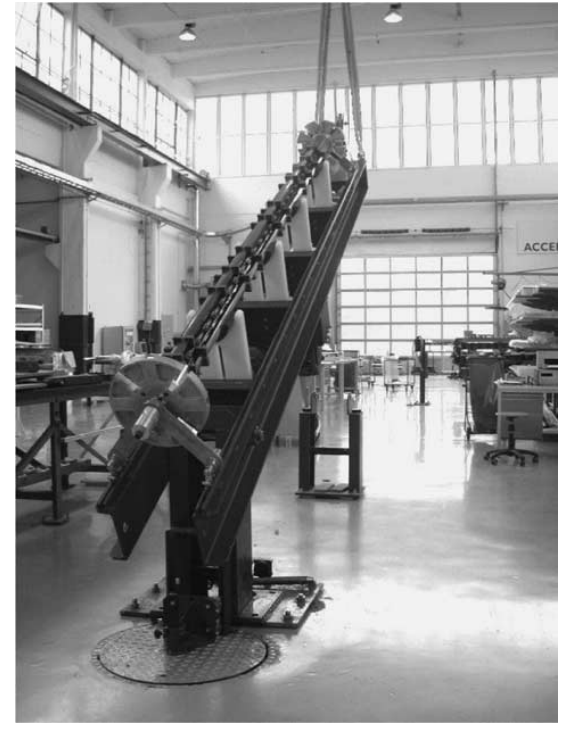

Fig. 6. Aperture assembly and collar stacking tooling.

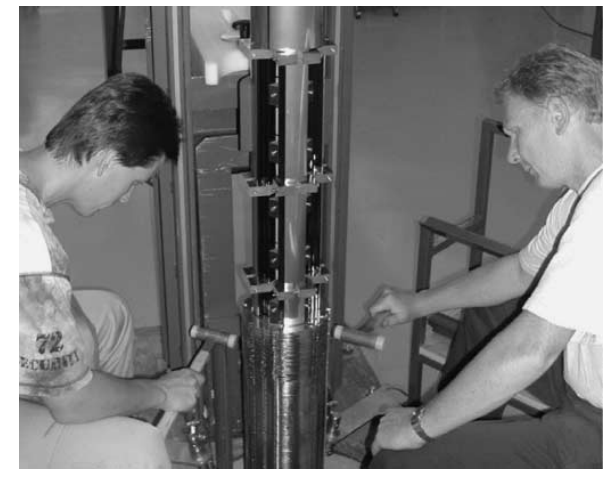

Fig. 7. Collar stacking.

\section{B. Collaring and Magnet Assembly}

Before the coils were assembled into apertures the quench heaters and mid-plane ground insulation sheets were glued on the layer 1-2 coils. The coils were then mounted onto a $3.5 \mathrm{~m}$ collapsible mandrel, and the longitudinal position of the coils adjusted for the small difference in length. The insulation sheets were then assembled on top of layer 3-4 coils and fixed with brackets. Full length stainless steel collaring shoes were also fixed with the brackets, and the tooling rotated into the vertical position for collar stacking, Fig. 6.

Collar stacking started at the return end using the round collars. About $10 \mathrm{~cm}$ of collars were stacked and tapped into position, Fig. 7. As the collars were stacked, the aperture was lowered into a hole in the floor so that the assembly team stayed on floor level. The collars were packed in boxes, organized in the correct orientation for mounting. This saves time and reduces errors in stacking. It took about 8 hours to stack the $3.5 \mathrm{~m}$ high aperture.

Full length pushing bars were mounted around the assembly and fixed into flanges at the top and bottom of the aperture. The assembly was then moved into the collaring press. Starting at the middle, the assembly was massaged with eight pushing rams pro-

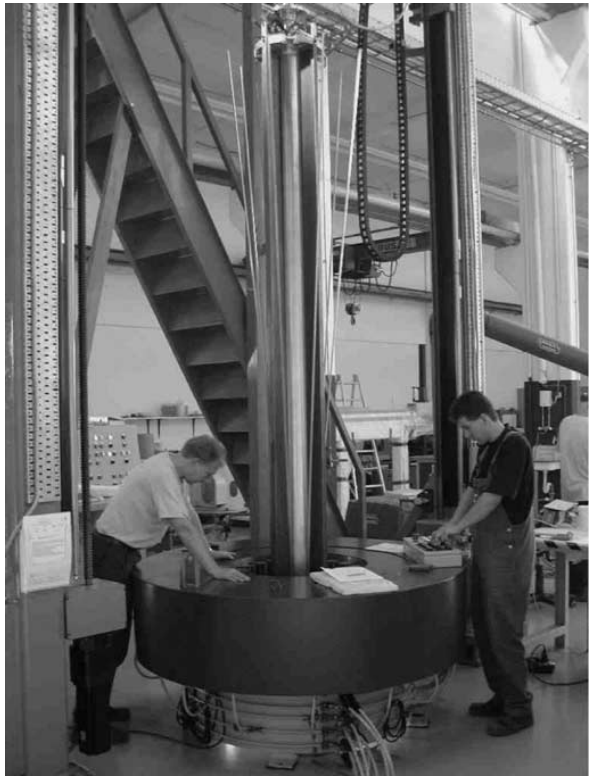

Fig. 8. Collaring of the aperture with full length keys.

ducing about $20 \mathrm{MPa}$ in the coils. Subsequently, the collars were fully compressed and the eight $3.5 \mathrm{~m}$ keys were partly inserted at the bottom, Fig. 8. The aperture was lowered in $200 \mathrm{~mm}$ steps and at each level the keys were pushed about $70 \%$ into the key slots. With the collar and key press engaged, the pre-stress in the coils was about $80 \mathrm{MPa}$, which then dropped to about $50 \mathrm{MPa}$ when the press was released. At this stage an intermediate electrical check was made. The keys were then pushed fully in and the pressure increased to about $100 \mathrm{MPa}$. After release, the pressure dropped to $75 \mathrm{MPa}$, and after ten minutes the coil pressure reduced another $5 \mathrm{MPa}$ due to creep. A final electrical check was then made, and the collapsible mandrel extracted.

After collaring, sixteen coil leads and an identical number of quench heater wires exit each aperture. Seven soldered joints were made in the compact multilayer connection box to connect the coils. The box was designed to minimize its length, and to keep the sections of the cable parallel to the magnet axis as short as possible. The box also provides mechanical support and insulates the cables and joints. The first and second layers, shown in Fig. 9, are used for the first joints and for routing of the quench heater wires. The other three layers hold two joints each. The final layer has the single central joint, to which the quench detection voltage wires are soldered. The cables were bonded into the connection box channels with a two part epoxy resin. A short $100 \mathrm{~mm}$ long expandable mandrel was used to stop the resin flowing into the aperture during assembly.

For the final magnet assembly, the collared apertures were mounted with the connection end facing down, Fig. 10. The yoking bars were inserted into the slots in each aperture to fix them in place, and the yoke laminations lowered over the apertures. Pneumatic rams were used to push the laminations into position and the elastic pins to lock them. Two 20 tonne rams were used to compress the assembly longitudinally every $80 \mathrm{~cm}$, which reduced the length of the stacked laminations by about 5 $\mathrm{mm}$ for each compression cycle. The end-plate was positioned and four tie rods welded to lock the magnet at the correct length. 


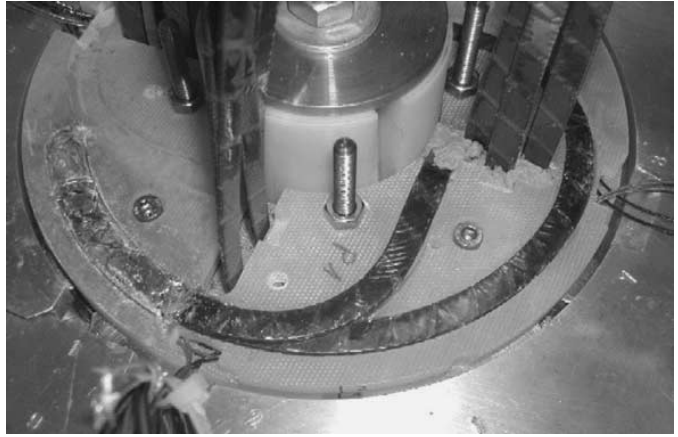

Fig. 9. First and second layers of the connection box, showing the first cable joint (left) and routing of the quench heater wires (center and right).

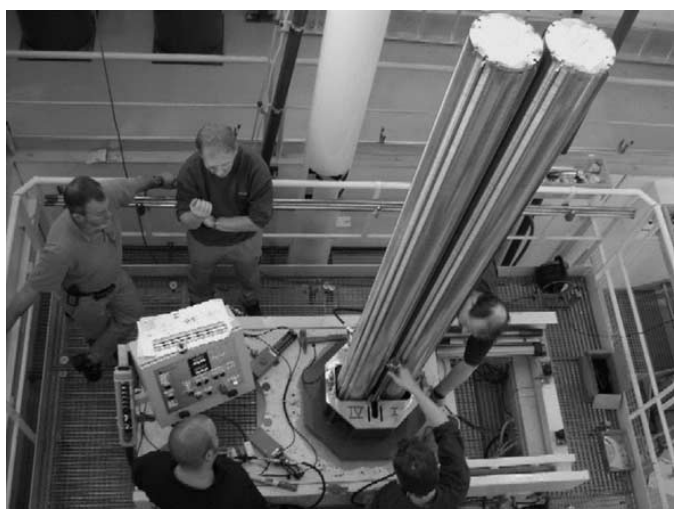

Fig. 10. Yoking of the MQY pre-series magnet.

\section{Warm Field Measurements}

As part of the acceptance tests in the factory, warm field measurements were performed on individual apertures before and after yoking. The average integral transfer function of the collared apertures is $40.50 \mathrm{~T} / \mathrm{m} / \mathrm{kA}$, and $44.18 \mathrm{~T} / \mathrm{m} / \mathrm{kA}$ after yoking, in very good agreement with expectations. The magnetic length of the apertures is $3.44 \mathrm{~m}$, and the difference between the two less than $0.5 \mathrm{~mm}$.

The field multipoles are shown in Fig. 11. The $b_{10}$ allowed multipole, less sensitive to coil size, closely matches the design value, both in the straight section and in the ends. As the coils in the two apertures were differently shimmed to correct for undersize, differences in $\mathrm{b}_{6}$ between the apertures could be expected. Indeed, aperture A2 was shimmed symmetrically on the median

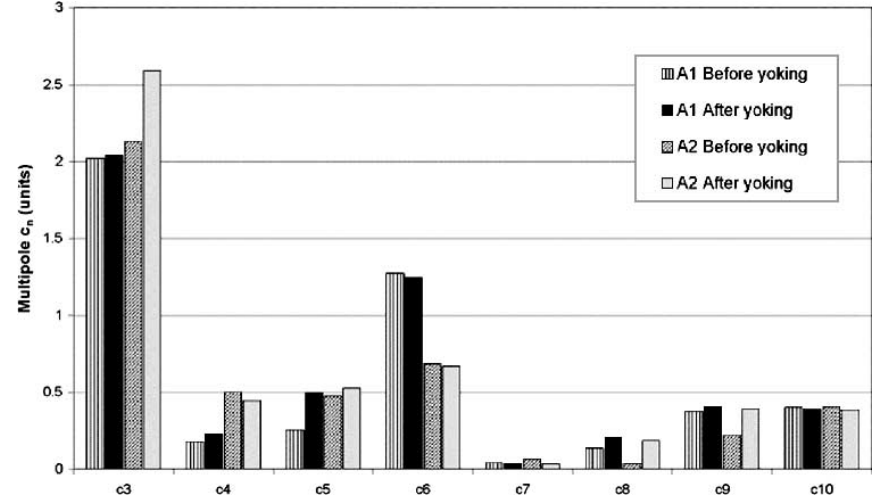

Fig. 11. Field multipoles measured at room temperature in the first pre-series MQY quadrupole. The multipoles $\left(c_{n}=\sqrt{ }\left(a_{n}^{2}+b_{n}^{2}\right)\right)$ are given in units of $10^{-4}$ of the main quadrupole field at the reference radius of $17 \mathrm{~mm}$.

plane, and the measured $\mathrm{b}_{6}$ corresponds well to the design value. For the same reason of uneven coil sizes, the nonallowed multipoles, in particular $b_{3}$ and $a_{3}$, are expected to be of the order of a few units.

\section{CONCLUSIONS}

As part of the industrialization program for the MQY superconducting quadrupoles for the LHC insertions, two pre-series magnets were built by ACCEL Instruments, and the production tooling and assembly processes successfully commissioned. The first pre-series magnet fulfilled the acceptance tests and was delivered to CERN for cold testing. The initial cold test results are very encouraging, as the magnet reached $3900 \mathrm{~A}, 8 \%$ above its nominal current, without a training quench. Further tests are in progress.

\section{ACKNOWLEDGMENT}

The authors would like to thank the ACCEL technicians responsible for the magnet production for their excellent work, and the long hours devoted to this magnet project.

\section{REFERENCES}

[1] R. Ostojic, "The LHC insertion magnets," IEEE Trans. Appl. Supercond., vol. 13, no. 2, pp. 1309-1312, June 2003.

[2] G. Kirby et al., "Performance of the 1-m model of the $70 \mathrm{~mm}$ bore twin-aperture quadrupole for the LHC insertions," IEEE Trans. Appl. Supercond., vol. 11, no. 1, pp. 1641-1644, March 2001. 